\title{
DESIGN AND DEVELOPMENT OF GASTRORETENTIVE DRUG DELIVERY SYSTEM OF CIPROFLOXACIN HYDROCHLORIDE
}

\author{
VIBIN BOSE R, JEGANATH S*, RAMYA SREE K, SHERNI PRITHIBA JHANSI RANI S
}

Department of Pharmaceutics, School of Pharmaceutical Sciences, Vels Institute of Science, Technology and Advanced Studies, Pallavaram, Chennai, Tamil Nadu, India. Email: jeganaths@gmail.com

Received: 10 October 2018, Revised and Accepted: 11 December 2018

\section{ABSTRACT}

Objective: The aim is to prepare the floating tablet of ciprofloxacin and to improve their bioavailability in the treatment against the Gram-positive and Gram-negative microorganisms. Ciprofloxacin HCL is an acidic drug used for respiratory tract infection, diarrhea, skin infection, thyroid fever, and urinary tract infection. The ciprofloxacin HCL is primarily absorbed in the stomach and it has low bioavailability. Due to its low availability, it was chosen as an appropriate drug for the scheme of the gastroretentive floating drug delivery system.

Method: Ciprofloxacin $\mathrm{HCl}$ is an acidic drug which was made by wet granulation process using various polymers, which include hydroxypropyl methylcellulose K4M, Eudragit, and Guar gum with a different composition. The gas generating agents such as saleratus and citric acid were used for the preparation. The prepared granules were subjected to pre-compression parameters technique and the formulated tablets were subjected to post-compression parameters, respectively.

Result: The Fourier-transform infrared analysis reveal that the drug and excipients used for the formulations were compatible with each other. All formulated granules having good flow properties and all the post-compression parameter are within the limit in which the F4 formulation shows optimum drug release of about $98.7 \%$ at $12 \mathrm{~h}$ and which has the buoyancy lag time of about $134 \mathrm{~s}$ and floating time about $12.5 \mathrm{~h}$. Kinetic treatment revealed of the optimized preparation is based on Korsmeyer-Peppas model. The value n=0.861 states the process of non-Fickian diffusion.

Conclusion: Based on above observation found in the work, it was concluded that ciprofloxacin $\mathrm{HCl}$ can formulate as a floating drug delivery system which helps in increasing the gastric residence time, as a result, it increases the bioavailability and half-life of ciprofloxacin HCl.

Keywords: Floating tablets, Ciprofloxacin hydrochloride, Hydroxypropyl methylcellulose K4M, Buoyancy lag time.

(C) 2018 The Authors. Published by Innovare Academic Sciences Pvt Ltd. This is an open access article under the CC BY license (http://creativecommons. org/licenses/by/4. 0/) DOI: http://dx.doi.org/10.22159/ajpcr.2018.v11s4.31722

\section{INTRODUCTION}

The dynamically controlled system or floating system is low-density systems which possess enough buoyant property to float over the gastric contents and in the stomach they remain buoyant, and provide the prolonged action without changing the gastro emptying rate, which leads to an increase in gastroretention time, thereby it control the variation in plasma drug concentration [1]. Its importance includes lower dosing and fewer side effects and suitable for the drug which is easily absorbed in the stomach. The mechanism is that the floating drug delivery system has a bulk density lesser than the gastric fluids and thus they remain buoyant in the stomach for a long period of time without changing the gastro emptying rate. The major advantages are enhanced bioavailability, sustained release of drugs [2,3]. The hydroxypropyl methylcellulose (HPMC) K4M, Eudragit, and guar gum used as the polymers for the preparation of ciprofloxacin floating tablet.

\section{METHODS}

Ciprofloxacin was a gift sample obtained from the Micro Labs at Hosur. The HPMC K100M and Guar gum were buyed from Loba Chemicals, Mumbai. Saleratus, starch, citric acid, and Mg stearate were purchased from S.D. Fine Chemicals, Mumbai.

\section{Drug-polymer compatibility studies}

Fourier-transform infrared (FTIR) analysis

FTIR study is used to analyze the interactions between the drug, excipients, and the polymers. They should be compatible with each another to produce a safe, efficacious, and stable product.
The peaks and patterns of the pure drug and the peaks and patterns of the combination of drug and polymers were compared with each other [4].

\section{Preparation of ciprofloxacin hydrochloride floating tablet}

Ciprofloxacin $\mathrm{HCl}$ floating tablet was formulated by wet granulation technique, exploitation of numerous polymers such as HPMC K4M, Eudragit 100S, guar gum with a combination of sodium bicarbonate, and citric acid as the gas generating agent [5]. The various mixture of each formulated preparation is given in Table 1.

Ciprofloxacin $\mathrm{Hcl}$ is passed through sieve no.20. All the excipients were passed through sieve no. 40 . Mg stearate is gone through sieve no 60 . The shifted materials of ciprofloxacin $\mathrm{HCl}$ were geometrically mixed with the chemical compound and saleratus (sodium bicarbonate), and citric acid are blended for $10 \mathrm{~min}$. Then, add starch mucilage slowly dropwise manner to create a coherent mass. The granules were prepared by passing the coherent mass through sieve no.16. The obtained granules are collected and using the hot air oven, it will be dried at $40^{\circ} \mathrm{C} \pm 20^{\circ} \mathrm{C}$ for $2 \mathrm{~h}$. The dried granule was gone through sieve no.20. Magnesium stearate is added to the dried granules then subjected to pre-formulation studies [6]. The granules of all formulations were compressed into tablets by exploitation tablets punching machine.

\section{Preformulation studies}

Bulk density

The bulk density is defined as the ratio between a given mass of granules or powder and its bulk volume [3]. The exactly weighed amount of granules was carefully placed into a $100 \mathrm{ml}$ measuring cylinder, from 
which the initial volume was measured, and it is calculated by the formulae [7].

Bulk density $=$ Weight of granules/bulk volume of granules

\section{Tapped density}

Tapped density is defined as the ratio between a given mass of granules or powder and the constant or fixed volume of the granules or powder after tapping.

Tapped density $=$ Weight of granules/tapped volume of granules

\section{Angle of repose}

The angle of repose is the maximum angle possible between the surface of the pile of powder and horizontal plane. The fixed funnel method is used to determine the angle of repose of the power or granules and to study the flow property of the powder or granules. The angle of repose $(\theta)$ can be determined by the formulae [8].

$$
\theta=\operatorname{Tan}^{-1}(\mathrm{~h} / \mathrm{r})
$$

Where,

$\theta=$ Angle of repose,

$\mathrm{h}=$ Height of the powder cone,

$r=$ Radius of the powder cone.

\section{Compressibility index (CI) and Hausner ratio}

It is a popular method of predicting the flow characteristics of granules and powder. The Hausner ratio and the CI are obtained by evaluating the tapped density and bulk density of a powder or granules.

\section{C.I = Tapped density-bulk density $\times 100$ Tapped density}

Hausner ratio $=$ Tapped density $/$ bulk density

\section{Characterization of ciprofloxacin $\mathrm{HCl}$ floating tablets \\ General appearance}

The general appearance includes the measurement such as a tablets shape, size, color, presence or absence of odor and taste, physical flows, surface textures, and consistency [9].

\section{Thickness}

The thickness of ciprofloxacin $\mathrm{HCl}$ floating tablets was measured using Vernier calipers. The thickness must be controlled to facilitate packaging.

\section{Hardness or crushing strength test}

Hardness is defined as the force that required breaking a tablet across a diameter [3]. The hardness of the tablet is determined using the monsanto hardness tester.

\section{Weight variation test}

The under medication or overdose can be possible, if any variation in the weight of the tablet. Therefore, tablet of each batch should have uniform weight. From each formulation 20 tablets were selected randomly and weigh it individually, and the individual tablet weight is noted. From the total weight of all tablets, the average weight of the tablet was calculated. The individual weights were compared with the average weight. Not more than two tablets must differ from the average weight. The percentage deviation was determined by the following formulae [10].

$$
\text { Percentage deviation }=\frac{\text { Individual weight }- \text { Average weight }}{\text { Average } \text { weight }} \times 100
$$

\section{Friability test}

It is studied to ensure the capacity of the tablets to withstand shock, while handling, transportation, processing, and packaging. It is usually measured using Roche Friabilator [11]. A maximal weight loss should not be exceeding $1 \%$ of the initial weight of the tablets after 100 evolutions (25RPM) are considered generally acceptable. The percent friability was obtained using the formula.

$$
\text { friability }=\frac{\left(w_{1}-w_{2}\right)}{w_{1}} \times 100
$$

Where,

$\mathrm{W}_{1}=$ Weight of tablets before the test

$\mathrm{W}_{2}=$ Weight of tablets after the test

\section{Estimation of drug content}

From each formulation 10 tablets were taken and which is weighed and powered the amount of powered equivalent to $100 \mathrm{mg}$ of ciprofloxacin $\mathrm{HCl}$ was transfer into $0.1 \mathrm{~N} \mathrm{HCl}$ containing volumetric flask of capacity $100 \mathrm{ml}$. From the prepared $1 \mathrm{ml}$ of sample was withdrawn and diluted to $10 \mathrm{ml}$ using $0.1 \mathrm{~N} \mathrm{HCl}$ and the resulting solution absorbance was observed at $277 \mathrm{~nm}$ [8].

\section{Floating test}

The formulated tablet was kept in $100 \mathrm{ml}$ beaker having $0.1 \mathrm{~N} \mathrm{HCl}$. The time difference between introducing the dosage form and there buoyancy on $0.1 \mathrm{~N} \mathrm{HCl}$ and the time at which the drug remain buoyant was observed [12].

\section{Buoyancy lag time}

The time required for a drug to emerge on the surface of the medium is known as floating lag time (FLT) [13]. Total duration of time during which the drug remains buoyant is known total floating time (TFT).

\section{In vitro release studies}

The in vitro studies were done using USP Type II dissolution test apparatus, and it is allowed to rotate at a speed of $50 \mathrm{rpm}$. The $900 \mathrm{ml}$ of $0.1 \mathrm{~N} \mathrm{HCl}$ was poured in the dissolution medium and dissolution jar is maintained at $37 \pm 0.5^{\circ} \mathrm{C}$. One of the formulated tablet was kept inside

Table 1: Formulation of ciprofloxacin HCl floating tablets

\begin{tabular}{llllllll}
\hline Formulations & $\begin{array}{l}\text { Ciprofloxacin } \\
\text { Hcl }\end{array}$ & $\begin{array}{l}\text { HPMC } \\
\text { K4M }\end{array}$ & $\begin{array}{l}\text { Eudragit } \\
\mathbf{1 0 0 S}\end{array}$ & $\begin{array}{l}\text { Guar } \\
\text { gum }\end{array}$ & $\begin{array}{l}\text { Sodium } \\
\text { bicarbonate }\end{array}$ & $\begin{array}{l}\text { Citric } \\
\text { acid }\end{array}$ & $\begin{array}{l}\text { Starch } \\
\text { stearate }\end{array}$ \\
\hline F1 & 250 & 150 & - & - & 50 & 15 \\
F2 & 250 & - & 150 & - & 50 & 25 \\
F3 & 250 & - & - & 150 & 50 & 15 \\
F4 & 250 & 75 & 75 & - & 5 & 15 \\
F5 & 250 & - & 75 & 75 & 50 & 15 \\
F6 & 250 & 75 & - & 75 & 50 & 15 \\
F7 & 250 & 50 & 50 & 50 & 50 & 15 & 15 \\
\hline
\end{tabular}

HPMC: hydroxypropyl methylcellulose 
the dissolution medium, after 1-h time interval $10 \mathrm{ml}$ of sample was withdrawn, and the absorbance is noted. The sample is collected up to $12 \mathrm{~h}$ and replaced with the same volume of medium. After suitable dilution, the samples were analyzed at $277 \mathrm{~nm}$ using UV double beam spectrophotometer $[6,14]$.

\section{Release kinetics}

The data observed from the in vitro studies were fitted to different kinetic equations which includes zero-order, first-order, KorsmeyerPeppas model, and Higuchi model [15].

$$
\begin{aligned}
& \text { Zero-order equation: }\left(\mathrm{Q}=\mathrm{Q}_{0}-\mathrm{k}_{0} \mathrm{t}\right) \\
& \text { First-order equation: }\left(\mathrm{In} \mathrm{Q}=\mathrm{Q}_{0}-\mathrm{K}_{1} \mathrm{t}\right) \\
& \text { Higuchi equation: }\left(\mathrm{Q}=\mathrm{K}_{2} \mathrm{t}^{1 / 2}\right) \\
& \text { Korsmeyer-peppers: }\left(\mathrm{Q} / \mathrm{Q}_{0}=\mathrm{K}^{\mathrm{n}}\right)
\end{aligned}
$$

\section{RESULTS AND DISCUSSION}

Preformulation studies of granules of ciprofloxacin $\mathrm{HCl}$ floating tablets

The granules of ciprofloxacin $\mathrm{HCl}$ floating tablets were formulated by wet granulation method. The prepared granules are introduced to preformulation studies, and the results are presented in Table 2.

The bulk density of the granules ranges from 0.32 to 0.393 . The tapped density of the granules ranged from 0.417 to 0.49 . The angle of repose ranges from $22^{\circ} 71^{\prime}$ to $26^{\circ} 15^{\prime}$. The $\mathrm{CI}$ and Hausner's ratio of the prepared granules ranged from 9.86 to 15.39 and 1.12 to 1.18 , respectively. The results showed that the granules of all formulations showed excellent flow properties.

\section{Characterization of ciprofloxacin $\mathrm{HCl}$ floating tablets}

\section{General appearance}

The prepared tablets were estimated for organoleptic characters. The tablets are circular in shape, yellowish in color, with no characteristic odor. All tablets showed elegance in appearance.

The compressed tablet was estimated by various physical parameters. The results are presented in Table 3 . The rigidity of the tablets ranges from 4.84 to 5.56 and percentage friability of all formulation within the range of $0.23-0.40 \%$. The thickness ranged from $4.1 \mathrm{~mm}$ to $4.4 \mathrm{~mm}$. Here, all the parameters are within the acceptable range. Hence, all the formulated tablets were falls within limits.

\section{Weight variation test}

All the formulated tablets undergo the weight variation test, and their percentage weight variations were within the pharmacopeial range. As a result, the weight of all tablets shows the low standard deviation values and found to be uniform, and the results are shown in Table 4.

\section{Estimation of drug content}

Drug content estimation shows that all the batches of formulated tablets are within the prescribed limits. It reveals that the drug and the excipients were mixed properly and the results are given in Table 4.

\section{Buoyancy lag time}

It is the time required during which the drug remains buoyant on $0.1 \mathrm{~N}$ $\mathrm{HCl}$ was measured, and the results are given in Table 5. The buoyancy lag time value was seen in the range of 134-166 s.

\section{TFT}

It is defined as the total duration of time required during which the drug remains buoyant is measured, and the values were ranges between 356 and $485 \mathrm{~min}$ and the results are given in Table 5 .

\section{IR spectral analysis}

The IR spectral studies of pure ciprofloxacin HCL, HPMC K4M, Eudragit, and Guar gum were done to study the drug-polymer interactions. It states that the IR spectrum of pure ciprofloxacin HCL and polymers have similar fundamental peaks and patterns. It reveals that there is no significant interaction within the drug and polymers. The results are shown in Figs. 1-8.

\section{In vitro dissolution studies}

An in vitro study was done to evaluate the dissolution character of ciprofloxacin HCL from floating tablets using three polymers with different ratios. The in vitro evaluation results are presented in Table 6. The graphical representation of the data is shown in Fig. 9.

The percentage drug release of all prepared formulations after $12 \mathrm{~h}$

\begin{tabular}{|c|c|c|c|c|c|c|}
\hline S. No & $\begin{array}{l}\text { Formulation } \\
\text { Code }\end{array}$ & $\begin{array}{l}\text { Angle of } \\
\text { repose }\end{array}$ & $\begin{array}{l}\text { Bulk density } \\
(\mathrm{g} / \mathrm{cm})\end{array}$ & $\begin{array}{l}\text { Tapped density } \\
\text { (g/cm) }\end{array}$ & CI (\%) & $\begin{array}{l}\text { Hausner's } \\
\text { ratio }\end{array}$ \\
\hline 1 & F1 & $22^{\circ} 71^{\prime}$ & 0.32 & 0.49 & 11.22 & 1.16 \\
\hline 2 & $\mathrm{~F} 2$ & $22^{\circ} 9^{\prime}$ & 0.386 & 0.435 & 11.34 & 1.12 \\
\hline 3 & F3 & $24^{\circ} 5^{\prime}$ & 0.393 & 0.436 & 9.86 & 1.12 \\
\hline 4 & $\mathrm{~F} 4$ & $24^{\circ} 01^{\prime}$ & 0.375 & 0.429 & 12.59 & 1.14 \\
\hline 5 & F5 & $25^{\circ} 1^{\prime}$ & 0.371 & 0.417 & 11.16 & 1.13 \\
\hline 6 & F6 & $26^{\circ} 1^{\prime}$ & 0.380 & 0.448 & 10.714 & 1.10 \\
\hline
\end{tabular}
using HPMC K4M, Eudragit 100S, and guar gum was found to be 88.12\% (F1), 90.68\% (F2), and 73.45\% (F3), respectively. Moreover,

Table 2: Preformulation studies of granules of ciprofloxacin $\mathrm{HCl}$ floating tablets

\begin{tabular}{|c|c|c|c|c|c|}
\hline S. No. & Formulation code & Hardness $(\mathrm{kg} / \mathrm{cm})$ & Friability (\%) & Thickness (mm) & Diameter (mm) \\
\hline 1 & F1 & 4.85 & 0.631 & 4.17 & 10.19 \\
\hline 2 & F2 & 4.8 & 0.413 & 5.14 & 10.8 \\
\hline 3 & F3 & 5.1 & 0.462 & 5.16 & 11.0 \\
\hline 4 & F4 & 4.75 & 0.381 & 4.4 & 10.7 \\
\hline 5 & F5 & 4.5 & 0.54 & 4.16 & 10.9 \\
\hline 6 & F6 & 5.0 & 0.761 & 4.5 & 11.0 \\
\hline 7 & F7 & 4.8 & 0.62 & 4.2 & 10.8 \\
\hline
\end{tabular}

CI: Compressibility index

Table 3: Evaluation of ciprofloxacin $\mathrm{HCl}$ floating tablets 
Table 4: Weigh variation and estimation of drug content of floating tablets

\begin{tabular}{llll}
\hline S. No & $\begin{array}{l}\text { Formulation } \\
\text { code }\end{array}$ & $\begin{array}{l}\text { Weight } \\
\text { variation }\end{array}$ & Drug content (\%) \\
\hline 1 & F1 & $498 \pm 2.5$ & 98.12 \\
2 & F2 & $496 \pm 3.2$ & 97.23 \\
3 & F3 & $497 \pm 2.7$ & 98.63 \\
4 & F4 & $499 \pm 1.13$ & 99.54 \\
5 & F5 & $498 \pm 3.5$ & 97.83 \\
6 & F6 & $495 \pm 4.3$ & 97.38 \\
7 & F7 & $497 \pm 4.2$ & 99.17 \\
\hline
\end{tabular}

Table 5: FLT and floating time of different formulations

\begin{tabular}{llll}
\hline S.No & Formulation code & FLT (Sec) & Floating time (h) \\
\hline 1 & F1 & 150 & 10.0 \\
2 & F2 & 144 & 10.5 \\
3 & F3 & 151 & 8.0 \\
4 & F4 & 134 & 12.5 \\
5 & F5 & 154 & 9.0 \\
6 & F6 & 166 & 9.5 \\
7 & F7 & 140 & 11.0 \\
\hline
\end{tabular}

FLT: Floating lag time

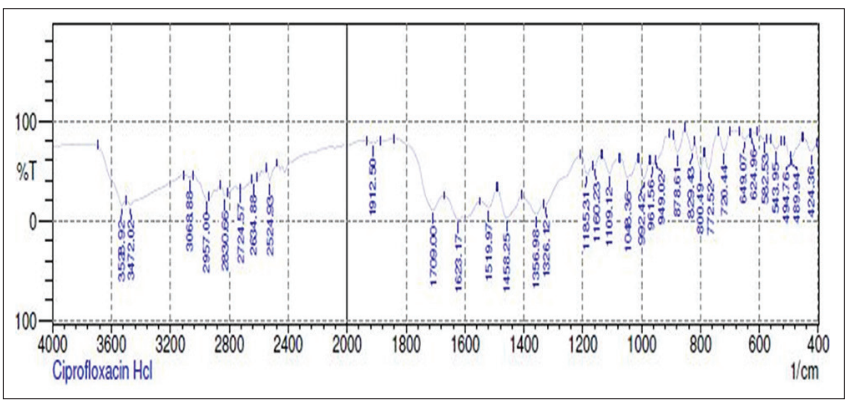

Fig. 1: Fourier-transform infrared spectrum of ciprofloxacin $\mathrm{HCl}$

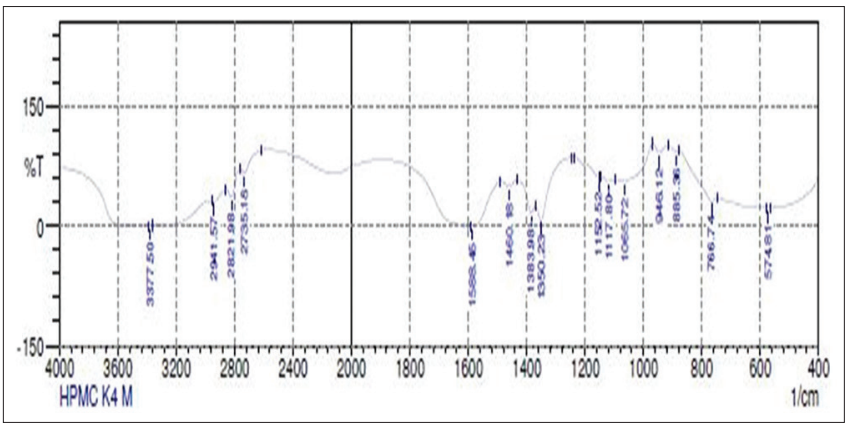

Fig. 2: Fourier-transform infrared spectrum of hydroxypropyl methylcellulose K4M

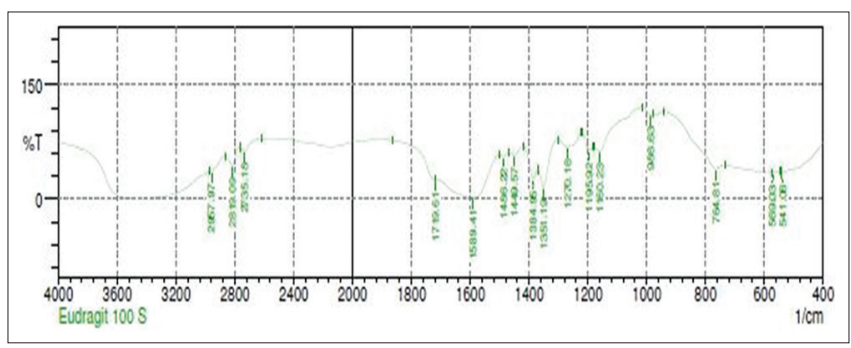

Fig. 3: Fourier-transform infrared spectrum of Eudragit 100S the percentage drug release of a combination of HPMC K4M with Eudragit $100 \mathrm{~S}$ is $98.87 \%$ (F4), Eudragit $100 \mathrm{~S}$ with guar gum is $85.67 \%$ (F5), HPMC K4M with guar gum is $79.93 \%$ (F6), and HPMC K4M with Eudragit 100 S and guar gum is $95.45 \%$ (F7).

From the in vitro evaluation study, it was observed that maximum drug release found in formulation F4 is $98.87 \%$. It shows that F4 formulation exhibits optimized drug release when compared with other formulation.

\section{Kinetic analysis of dissolution data}

The absorbed data were treated in case of zero-order, first-order, Korsmeyer- Peppas model, and Higuchi's model to study the mechanism of drug release of prepared formulations. The release rate kinetic data for all the formulations were given in Table 7 , the graphical representation of the data is shown in Figs. 10-13. The formulation showed high linearity when plotted in zero-order kinetics with regression coefficient values $\left(\mathrm{R}^{2}\right)$ between 0.993 and 0.998 .

Diffusion is the process in which the drug moved from the dosage matrix into the in vitro study fluid based on the concentrations. This is governed by Higuchi's equations, as the plot reveals the high linearity with regression coefficient values $\left(R^{2}\right)$ between 0.878 and 0.938 .

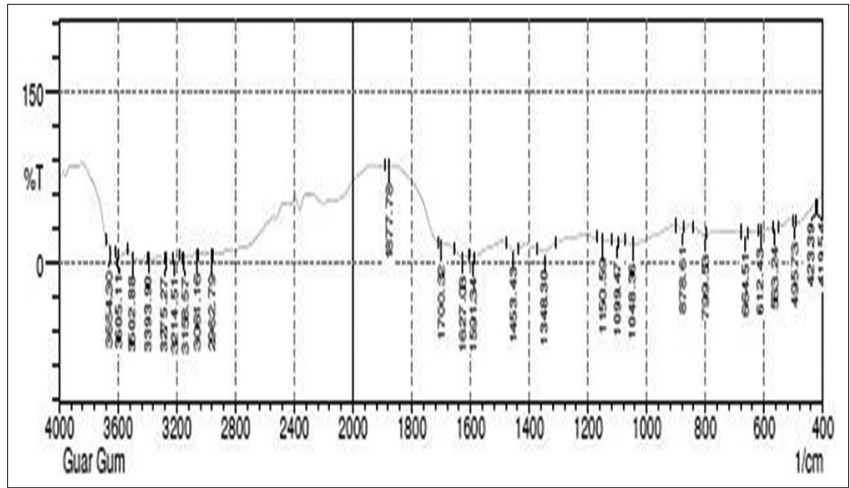

Fig. 4: Fourier-transform infrared spectrum of Guar gum

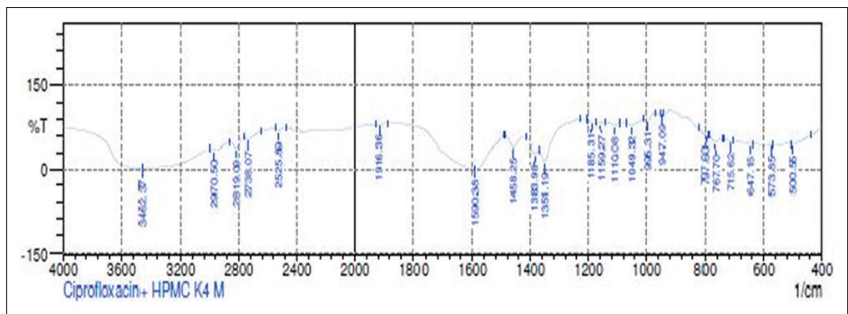

Fig. 5: Fourier-transform infrared spectrum of ciprofloxacin $\mathrm{HCl}$ and hydroxypropyl methylcellulose K4M

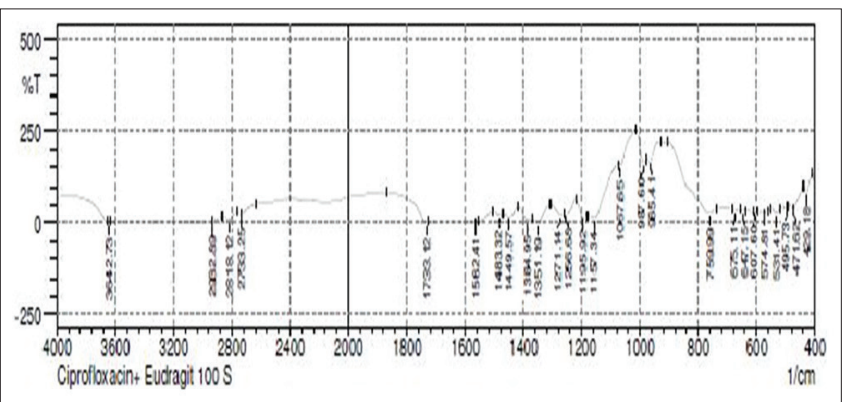

Fig. 6: Fourier-transform infrared spectrum of ciprofloxacin $\mathrm{HCl}$ and Eudragit 100S 
Table 6: Comparative in vitro dissolution study of ciprofloxacin $\mathrm{HCl}$ floating tablets (F1-F7)

\begin{tabular}{|c|c|c|c|c|c|c|c|}
\hline \multirow[t]{2}{*}{ Time (h) } & \multicolumn{7}{|c|}{ Cumulative $\%$ drug release } \\
\hline & F1 & F2 & F3 & F4 & F5 & F6 & F7 \\
\hline 1 & 11.22 & 9.43 & 8.24 & 12.18 & 9.91 & 10.51 & 10.98 \\
\hline 3 & 19.8 & 21.51 & 13.68 & 27.13 & 16.86 & 15.27 & 24.81 \\
\hline 4 & 27.01 & 29.94 & 18.7 & 36.78 & 24.2 & 21.38 & 31.04 \\
\hline 5 & 33.73 & 35.93 & 25.66 & 44 & 31.16 & 29.82 & 39.23 \\
\hline 6 & 39.84 & 41.8 & 30.18 & 52.43 & 37.4 & 36.17 & 45.58 \\
\hline 7 & 47.3 & 50.23 & 36.3 & 60.74 & 41.8 & 40.94 & 51.08 \\
\hline 8 & 53.04 & 58.17 & 42.04 & 69.05 & 50.23 & 48.15 & 61.47 \\
\hline 9 & 63.92 & 68.68 & 51.45 & 77.24 & 58.91 & 54.02 & 70.52 \\
\hline 10 & 71.98 & 75.28 & 57.81 & 85.43 & 68.07 & 62.57 & 81.64 \\
\hline 11 & 79.81 & 82.13 & 69.91 & 91.91 & 76.14 & 72.47 & 87.02 \\
\hline 12 & 88.12 & 90.68 & 73.45 & 98.87 & 85.67 & 79.93 & 95.45 \\
\hline
\end{tabular}

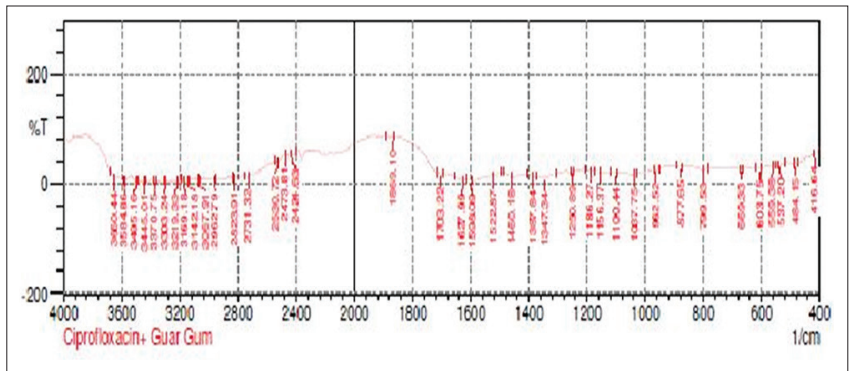

Fig. 7: Fourier-transform infrared spectrum of ciprofloxacin $\mathrm{HCl}$ and Guar gum

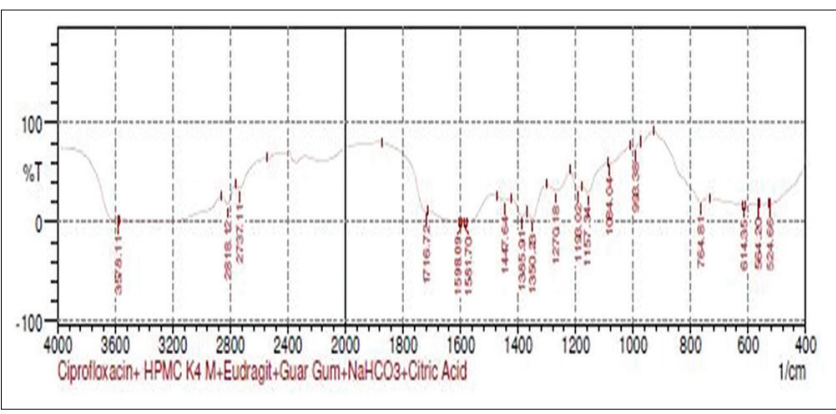

Fig. 8: Fourier-transform infrared spectrum of ciprofloxacin $\mathrm{HCl}$, hydroxypropyl methylcellulose K4M, Eudragit 100S, Guar gum, sodium bicarbonate, and citric acid

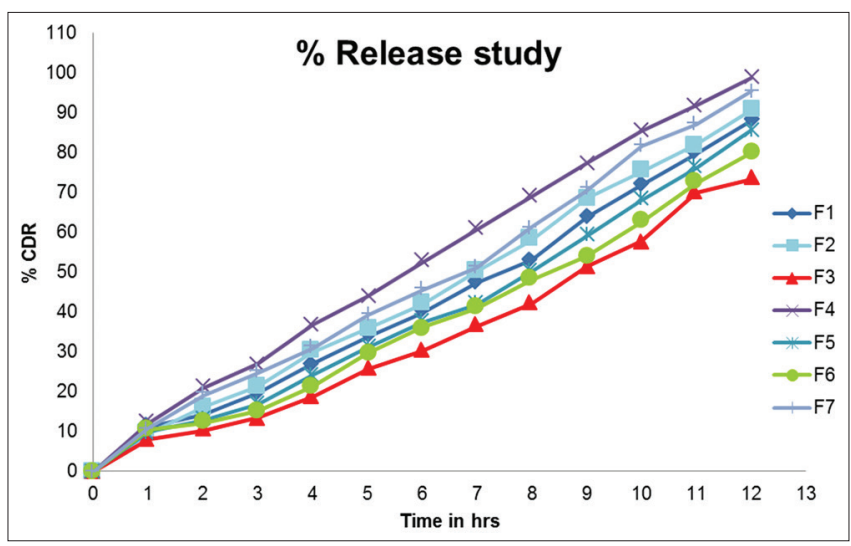

Fig. 9: Comparative in vitro dissolution study of ciprofloxacin $\mathrm{HCl}$ floating tablets (F1-F7)

Using Korsmeyer-Peppas model, if $\mathrm{n}=0.45$, it is Fickian diffusion, if $\mathrm{n}=0.45-0.89$ it is non-Fickian transport. Here, all the formulations

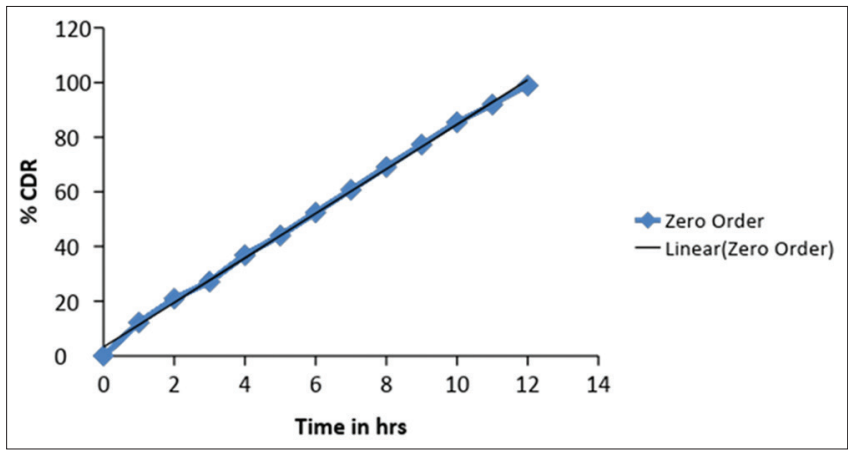

Fig. 10: Zero-order drug release kinetics of F4

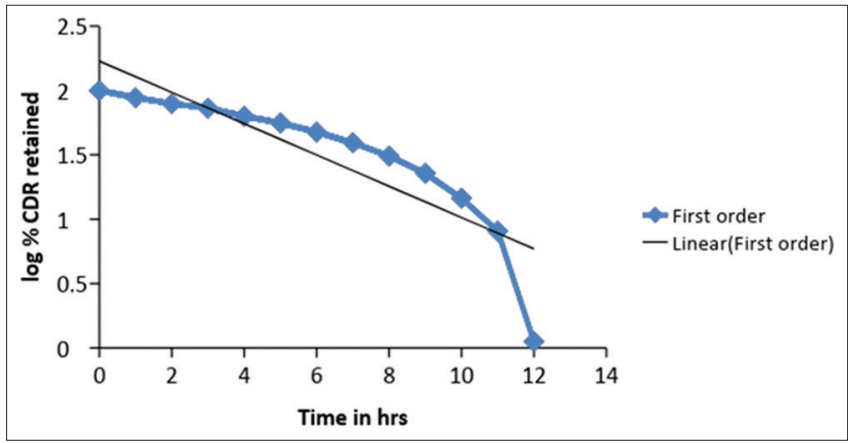

Fig. 11: First-order drug release kinetics of F4

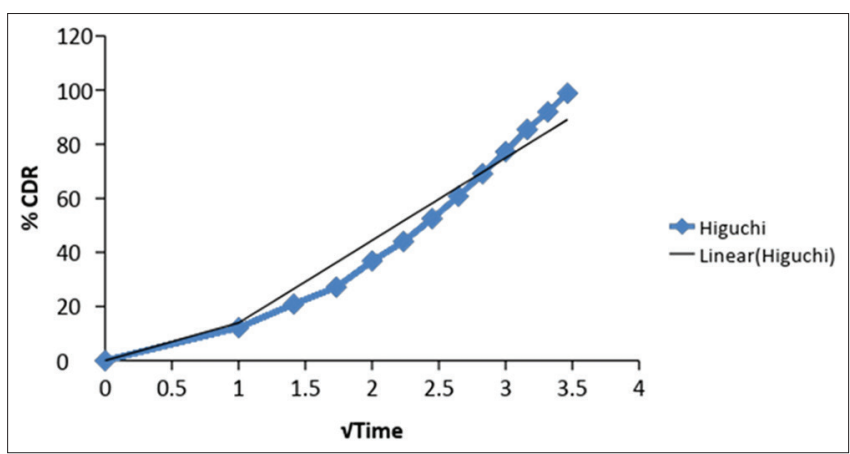

Fig. 12: Higuchi model of drug release kinetics for $F 4$

showed " $n$ " values between 0.806 and 0.929 . Hence, all the formulations follow non-Fickian diffusion transport mechanism. 
Table 7: Kinetic analysis of dissolution data

\begin{tabular}{|c|c|c|c|c|c|c|}
\hline \multirow[t]{2}{*}{ S. No } & \multirow[t]{2}{*}{ Formulation code } & \multicolumn{3}{|c|}{ Regression coefficient $\left(\mathrm{R}^{2}\right)$} & \multicolumn{2}{|c|}{ Korsmeyer' plot } \\
\hline & & Zero-order plot & First-order plot & Higuchi's plot & $\mathbf{R}^{2}$ & Slope (n) \\
\hline 1 & F1 & 0.993 & 0.886 & 0.896 & 0.970 & 0.887 \\
\hline 3 & F3 & 0.988 & 0.880 & 0.878 & 0.997 & 0.868 \\
\hline 4 & $\mathrm{~F} 4$ & 0.998 & 0.763 & 0.938 & 0.996 & 0.861 \\
\hline 5 & F5 & 0.988 & 0.880 & 0.878 & 0.998 & 0.806 \\
\hline 6 & F6 & 0.988 & 0.880 & 0.878 & 0.998 & 0.825 \\
\hline 7 & F7 & 0.995 & 0.832 & 0.912 & 0.990 & 0.877 \\
\hline
\end{tabular}

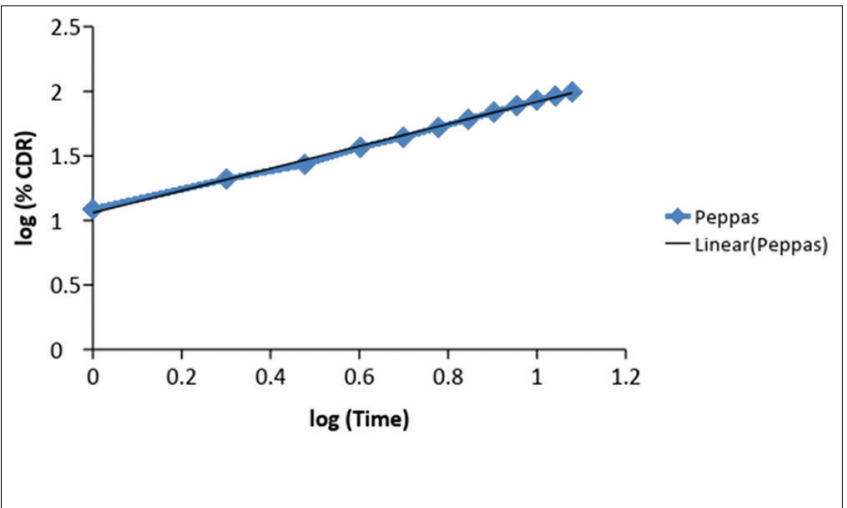

Fig. 13: Peppas model of drug release kinetics forF4

\section{CONCLUSION}

Hydrodynamically balanced tablets of ciprofloxacin $\mathrm{HCl}$ can be formulated with an approach to improve drug bioavailability and to increase gastric residence. The developed floating tablets of ciprofloxacin $\mathrm{HCl}$ were formulated using HPMC K4M, Eudragit100S, and guar gum as polymers and sodium bicarbonate combination with citric acid as the gas generating agent which is prepared by wet granulation technique and evaluated. The result states that all the parameters are within the range. When comparing all formulation, F4 showed optimized drug release of $98.87 \%$ at the end of $12 \mathrm{~h}$. The optimized F4 formulation showed buoyancy lag time of $134 \mathrm{sec}$ and floating time of $12.5 \mathrm{~h}$, respectively. Data obtained from the kinetic treatment show F4 formulations follow Korsmeyer-Peppas model. The $\mathrm{n}=0.861$ indicates the non-Fickian diffusion. From the above study, it was concluded that ciprofloxacin $\mathrm{HCl}$ can formulate as a floating drug delivery system with more bioavailable, safe, and economical drug and which helps to increase gastric residence time thereby it increases the bioavailability and half-life of ciprofloxacin $\mathrm{HCl}$.

\section{REFERENCES}

1. Garg R, Gupta GD. Progress in controlled gastroretentive delivery systems. Trop J Pharma Res 2008;7:1055-66.

2. Jeganath S, Shafiq MK, Mahesh PG, Kumar SS. Formulation and evaluation of non-effervescent floating tablet of linagliptin using lowdensity carrier. Drug Invent Today 2018;1:322-9.

3. Hilton AK, Deasy PB. In vitro and in vivo evaluation of an oral sustained release floating dosage form of amoxicillin trihydrate. Int $\mathrm{J}$ Pham 1992;86:79-88.

4. Seth PR, Tossounian J. The hydrodynamic ally balanced system, a novel drug delivery system for oral use. Drug Dev Ind Pharm 1984;10:313-39.

5. Whitehead L, Fell JT, Collett JH. Development of a gastro-retentive dosage form. Eur J Pharm Sci 1996;4:182.

6. Moes AJ. Gastro retentive dosage forms. Crit Rev Drug Carrier Syst 1993;10:143-95.

7. Hwang SJ, Park H, Park K. Gastric retentive drug-delivery systems. Crit Rev Ther Drug Carrier Syst 1998;15:243-84.

8. Mukhopadhyay S, Goswami L, Madhav NV, Upadhyaya K. Formulation and evaluation of floating bioadhesive tablets of ciprofloxacin hydrochloride by direct compression technique. Int J Pharm Pharm Sci 2010;2:113-5.

9. Yeole PG, Khan S, Patel VF. Floating drug delivery systems: Need and development. Indian J Pharm Sci 2005;67:265.

10. Yang L, Eshraghi J, Fassihi R. A new intragastric delivery system for the treatment of helicobacter pylori associated gastric ulcer: In vitro evaluation. J Control Release 1999;57:215-22.

11. Timmermans J, Moës AJ. Factors controlling the buoyancy and gastric retention capabilities of floating matrix capsules: New data for reconsidering the controversy. J Pharma Sci 1994;1:18-24.

12. Blanquet S, Zeijdner E, Beyssac E, Meunier JP, Denis S, Havenaar R, et al. Dynamic artificial gastrointestinal system for studying the behavior of orally administered drug dosage forms under various physiological conditions. Pharm Res 2004;4:585-91.

13. Salunke RJ, Shahi SR, Atram SC, Neb GB, Patil S. Formulation and evaluation of hydrodynamically balanced system of ciprofloxacin $\mathrm{HCl}$. Int J Pharm Res Dev 2009;7:001.

14. Mostafavi A, Emami J, Varshosaz J, Davies NM, Rezazadeh M. Development of a prolonged-release gastroretentive tablet formulation of ciprofloxacin hydrochloride: Pharmacokinetic characterization in healthy human volunteers. Int J Pharm 2011;2:128-36.

15. Srikanth MV, Sunil SA, Janakiram B, Murthy KV. Design and in vitro evaluation of effervescent gastric floating drug delivery systems of propranolol HCl. Invest Clin 2012;53:60-70. 